\title{
Artigo \\ Fogão solar tipo elíptico móvel: uma tecnologia alternativa para o processo de cocção de alimentos
}

\author{
Francisco José Sombra Jr ${ }^{[1]}$, Luiz José de Bessa Neto ${ }^{[2]}$, Edson Freire Targino ${ }^{[3]}$ e \\ Fabiana Karla de Oliveira Martins Varella Guerra ${ }^{[4]}$
}

\begin{abstract}
[1] Universidade Federal Rural do Semi-árido; fjsombrajunior@yahoo.com.br
[2] Universidade Federal Rural do Semi-árido; luizjbessa@outlook.com

[3] Universidade Federal Rural do Semi-árido; edsonfreire2030@ outlook.com

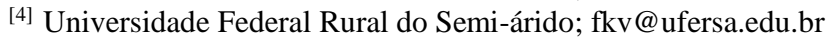

Recebido: 10/06/2020;

Aceito: 09/08/2020;

Publicado: 11/09/2020.

Resumo: A irradiação solar no Brasil tem valores bastante expressivos anualmente, e no que se refere ao território brasileiro, este recurso é responsável por atingir elevados números na geração de energia através da radiação solar em quase todo o ano, como acontece, por exemplo, na região Nordeste. Nesse sentido, este cenário favorável tem motivado a disseminação de diversas tecnologias utilizando a energia solar, assim como pesquisas relacionadas à utilização de diversos equipamentos, como o fogão solar para cocção de alimentos. Diante do exposto, o presente trabalho tem como objetivo desenvolver um fogão solar do tipo elíptico móvel, que configura-se como uma tecnologia alternativa para otimizar o processo de cocção de alimentos. Dessa maneira, com o intuito de verificar o desempenho do protótipo confeccionado, realizou-se o cozimento dos alimentos arroz, batata-doce, ovo e feijão. Aliado a isso, analisou-se os dados concernentes aos valores de temperatura, a irradiância solar e o tempo de cozimento durante o processo de cocção. Mediante o desenvolvimento deste trabalho, percebeu-se que os ajustes realizados da posição focal no decorrer dos ensaios proporcionaram ganhos significativos, denotando que o presente protótipo se apresenta como uma tecnologia alternativa útil para otimizar o processo de cocção de alimentos.

\section{Palavras-chave: Energia solar; Fogão solar elíptico; Cocção de alimentos}

Abstract: Solar irradiation in Brazil has very significant values annually, and with regard to the Brazilian territory, this resource is responsible for reaching high numbers in the generation of energy through solar radiation almost all year round, as happens, for example, in the region Northeast. In this sense, this favorable scenario has motivated the dissemination of several technologies using solar energy, as well as research related to the use of various equipment, such as the solar cooker for cooking food. Thus, in order to verify the performance of the prototype, rice, sweet potatoes, eggs and beans were cooked. Allied to this, the data concerning temperature values, solar irradiance and cooking time during the cooking process were analyzed. Through the development of this work, it was noticed that the adjustments made to the focal position during the tests provided significant gains, denoting that the present prototype presents itself as a useful alternative technology to optimize the cooking process.

Key-words: Solar energy; Elliptical solar cooker; Food cooking

\section{INTRODUÇÃO}

$\mathrm{O}$ Sol é a grande fonte de energia renovável do planeta. O aproveitamento adequado de sua energia é a alternativa mais ambientalmente correta, uma vez que é uma fonte abundante, permanente, renovável, limpa e disponível em todas as regiões do globo terrestre. Nessa conjuntura, o Brasil configura-se como o 
principal país do mundo em disponibilidade de energia solar, em virtude, maiormente, da sua localização geográfica privilegiada e pelo seu imenso território [1].

A energia solar no Brasil tem uma irradiação global média anual entre 1.200 e $2.400 \mathrm{kWh} / \mathrm{m}^{2}$, o que tem motivado a disseminação de centrais fotovoltaicas e pesquisas concernentes a utilização de diversos equipamentos, dentre estes, o fogão solar para cocção de vários alimentos [3-4]. Nesse sentido, o uso de fogões, fornos e secadores solar ganha um contexto de prioridade, devido, principalmente, a sua capacidade de mitigar os efeitos danosos do uso da lenha (evitando a emissão de toneladas de dióxido de carbono para a atmosfera) e pela opção de obtenção de alimentos a partir de frutas, verduras e legumes de alto grau de perecibilidade, que fazem parte de um universo de perda de alimentos em torno de 50\%. [5].

Aliado a isso, os fogões solares surgem como resposta ao uso dos fogões convencionais que utilizam gás ou lenha na cocção de alimentos, já que em termos globais a queima da lenha utilizada para essa finalidade atinge cerca de 2,5 bilhões de pessoas, dos quais 23 milhões são brasileiros [6]. De acordo com [7], esses fornos solares encontram ampla aplicação em todo o planeta, essencialmente na Ásia e África, com destaque para a Índia e China, haja vista que são os países que mais tem investido em programas sociais que viabilizam a construção de fogões solares à baixo custo.

Segundo [8] essa tecnologia visa utilizar a energia proveniente do sol, através dos raios solares em forma de calor para cozinhar ou pasteurizar os alimentos. Na literatura perduram quatro tipos de fogões solares: fogão solar do tipo painel, fogão solar do tipo parabólico, fogão solar do tipo elíptico e fogão solar do tipo caixa.

Por todo o exposto, o vigente trabalho tem como objetivo desenvolver um fogão solar do tipo elíptico móvel, que configura-se como uma tecnologia alternativa, de baixo custo e promissora para otimizar o processo de cocção de alimentos. Também foi avaliado o desempenho do protótipo confeccionado, e realizou-se o cozimento dos alimentos arroz, batata doce, ovo e feijão. Ademais, analisou-se os dados obtidos em campo nos ensaios realizados, a saber, temperatura, irradiância solar e o tempo de cozimento durante o processo de cocção.

\section{FOGÃo SOLAR TIPO ELÍPTICO}

O fogão solar de geometria elíptica configura-se como um fogão do tipo concentrador, que capta a irradiação solar e a concentra em uma região focal, onde se posiciona o absorvedor ou panela, promovendo a cocção dos alimentos [1]. Entretanto, para que haja essa captação e reflexão da luz solar são necessários refletores, geralmente espelhos ou adesivos de papel alumínio distribuídos em uma superfície de forma côncava com alto grau de polimento e uma estrutura de metal para comportar a face refletora [2]. Além disso, a área da superfície absorvedora é menor do que a área do dispositivo de captação da energia solar, de modo a aumentar a intensidade energética.

É oportuno salientar, que as principais características desse tipo de fogão solar são a temperatura no foco que pode atingir $350^{\circ} \mathrm{C}$ ou mais, dependendo do tamanho da parabólica ou da elipse refletora; tempo de aquecimento rápido, se comparado com os outros modelos de fogões solares. Ressaltasse, ademais, que o fogão solar de geometria elíptica necessita de luz solar direta, pelo qual faz-se essencial um mecanismo de acompanhamento da trajetória do sol com reorientação, usualmente a cada 30 minutos.

Aliado a isso, esse tipo de fogão solar apresenta um esfriamento repentino do alimento se porventura houver desvio de foco ou nebulosidade acentuada, alguns são instáveis à ventos, bem como evidencia risco de fogo ou queimaduras, além de danos aos usuários devido aos raios refletidos e ao fato de ficar exposto ao sol [3].

No que concerne aos fogões concentradores, primeiramente tem-se o processo de reflexão dos raios solares e, posteriormente, ocorre a concentração da energia térmica em um ponto focal no fundo da panela, suscitando, dessa maneira, a cocção do alimento [9]. A Figura 1 ilustra o princípio de funcionamento de um fogão solar do tipo concentrador de estrutura elíptica. 


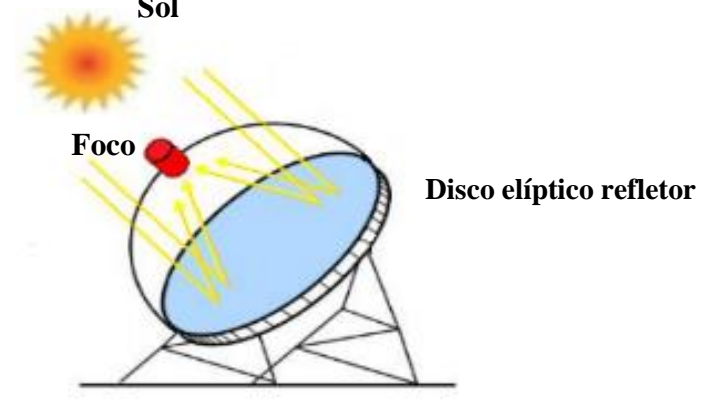

FIGURA 1. Princípio de funcionamento de um fogão solar concentrador de estrutura elíptica (Adaptado de [3]).

Pode-se citar como uma das principais vantagens desse tipo de fogão solar a capacidade de gerar maiores potências em menores tempos de cozimento a depender do tipo de superfície refletora, área de reflexão e condições climáticas favoráveis. É muito importante que durante o processo de cocção dos alimentos seja utilizada uma panela na cor preta, para absorver melhor a irradiação solar sobre ela incidida, aumentando a eficiência do fogão [3].

\section{MATERIAIS E MÉTODOS}

\subsection{Protótipo Desenvolvido}

Com o intuito de aprimorar e viabilizar a utilização da tecnologia de cocção de alimentos através da irradiação solar, foi confeccionado um fogão solar com duplos refletores de geometria elíptica e movimentos relativos entre si, sendo ambos equidistantes ao ponto focal. Almejando eficiência considerável em relação a modelos desenvolvidos pela literatura, o protótipo foi desenvolvido com o auxílio de materiais reciclados obtidos em sucatas e obras, sendo o mesmo considerado de baixo custo.

Dessa maneira, a inserção do movimento nos refletores fez-se necessária para um melhor aproveitamento na reflexão dos raios solares no ponto focal, elevando a capacidade de reflexão dos raios no fundo da panela. Devido aos movimentos de rotação e translação da Terra, há a imprescindibilidade de reajustar os refletores a cada 30 minutos, aproximadamente, mantendo-os assim, por um período maior a incidência dos raios solares no recipiente de cocção, que se localiza no ponto focal.

Conforme supracitado, os materiais foram adquiridos em sucatas, sendo alguns doados e outros comprados por valores atrativos. Para os refletores, por exemplo, foram utilizadas duas antenas do tipo parabólica. Ao observá-las, pode-se perceber que o receptor de sinais de satélites LNB (Low Noise Block conversor de baixo ruído), não fica localizado exatamente ao centro da antena, todavia, localizando-se no foco. Essa incompatibilidade em relação ao foco de uma parábola dar-se devido às antenas utilizadas terem geometria elíptica com foco deslocado, representado por uma secção de um elipsoide. A Figura 2 evidencia o tipo de antena utilizada apresentando a descrição de seus componentes.

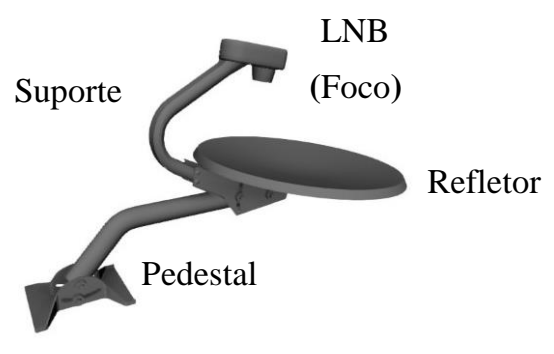


FIGURA 2. Modelo da antena utilizada (Autoria própria).

Fundamentado em experimentos anteriores, optou-se por dispor os refletores em posição de forma que ambos ficassem a, aproximadamente, 90 graus um do outro e equidistantes ao eixo onde se localiza os focos das mesmas. Dessa forma, os dois anteparos de reflexão sempre deverão ficar em posição oposta ao sol, evitando o sombreamento nas superfícies refletoras, o que aumenta significativamente a área de reflexão dos raios solares.

Com o intuito de executar a confecção do presente fogão solar do tipo elíptico móvel, foi necessário desenvolver uma base que atendesse às especificações citadas. Para tal, utilizou-se restos de sucatas de ferro como tubos, barras chatas e parafusos, além de eletroduto rígido e conexões em PVC. Todas as peças foram moldadas de acordo com as características de cada material, evitando que possíveis falhas mecânicas pudessem ocorrer em condições normais de utilização.

Visando aumentar o número de possibilidades de configurações do protótipo, resolveu-se confeccionar uma base de ferro que possibilitasse futuras modificações na angulação entre os refletores. Assim sendo, a base de ferro foi produzida possibilitando a regulagem entre os dois refletores; entre os refletores e seus respectivos pedestais de sustentação; regulagem na altura do eixo do ponto focal; e de toda a estrutura de ferro em relação à base de madeira, que serve de sustentação a todo o conjunto.

A Figura 3 mostra a base e os seus elementos numerados de 1 a 3. Em (1) são mostrados os suportes de fixação dos pedestais com os refletores; em (2) é possível ver o eixo vertical de convergência dos focos que possuem furos para a regulagem de altura do suporte da panela; e finalmente em (3), mostra-se que entre os suportes 1 , há a possibilidade de regular o ângulo entre eles, caso seja necessário.

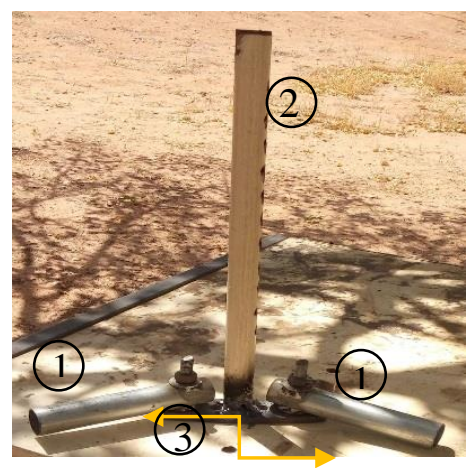

FIGURA 3. Base do fogão solar tipo elíptico móvel confeccionado (Autoria própria).

Visando reduzir os custos, para não utilizar o espelho como material reflexivo, optou-se por utilizar a fita adesiva metalizada cromada, encontrada facilmente no comércio. Ela é bastante utilizada em situações que se deseja obter maior isolação térmica devido ao seu alto poder de reflexão da radiação solar, como nas instalações e manutenções de centrais de ares-condicionados, além de ser menos onerosa quando comparada ao espelho.

Ademais, os pedestais originais das antenas foram substituídos por dois pedestais confeccionados com eletrodutos rígidos de 1 1/4 de polegada e duas curvas tipo joelho em PVC de mesma dimensão. Essas peças devidamente medidas, cortadas e montadas, formaram dois pedestais em formato de "L".

Nessa conjuntura, a Figura 4 mostra em (a) a preparação das superfícies dos refletores, onde foi necessário retirar todas as impurezas através de procedimentos de limpeza; e em (b), a aplicação da fita metálica propriamente. Posteriormente, a preparação das duas superfícies refletoras, todas as peças do fogão solar em questão foram encaixadas. 


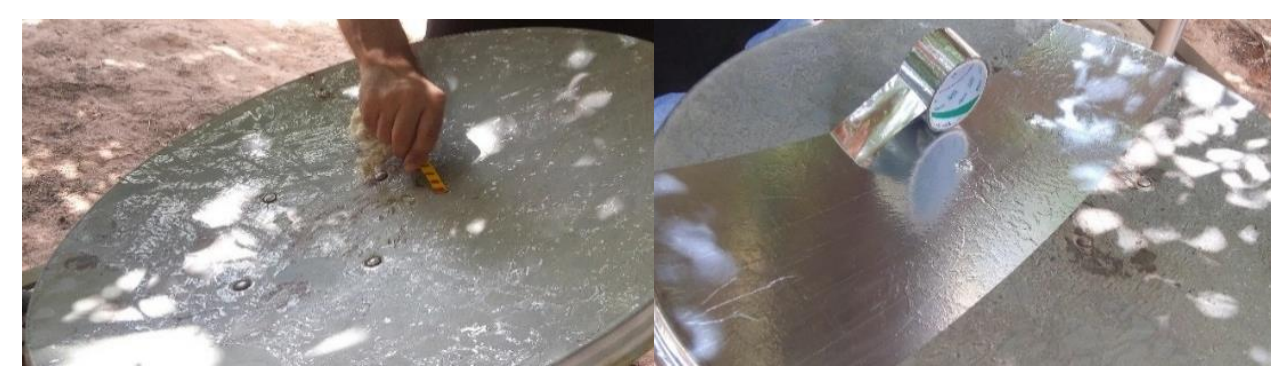

(a)

(b)

FIGURA 4. (a) Preparação da superfície; (b) Aplicação da fita (Autoria própria).

O ponto focal do fogão foi encontrado partindo de que o foco da antena localiza-se na posição do LNB (vide Figura 2). Manuseando uma antena por vez, as mesmas foram posicionadas próximas à base de ferro de forma que o LNB ficasse ao longo do eixo vertical, local onde os dois focos se convergem e se localiza a panela. Dessa forma, os pedestais foram devidamente calibrados no suporte de fixação, garantido que o ponto de convergência entre os focos sejam incidentes sempre no mesmo eixo vertical. A Figura 5 mostra em (a) o foco com concentração adequada; em (b), o foco mais disperso; e em (c), a panela centralizada no foco, momento indicado para iniciar a realização dos ensaios de cocção.

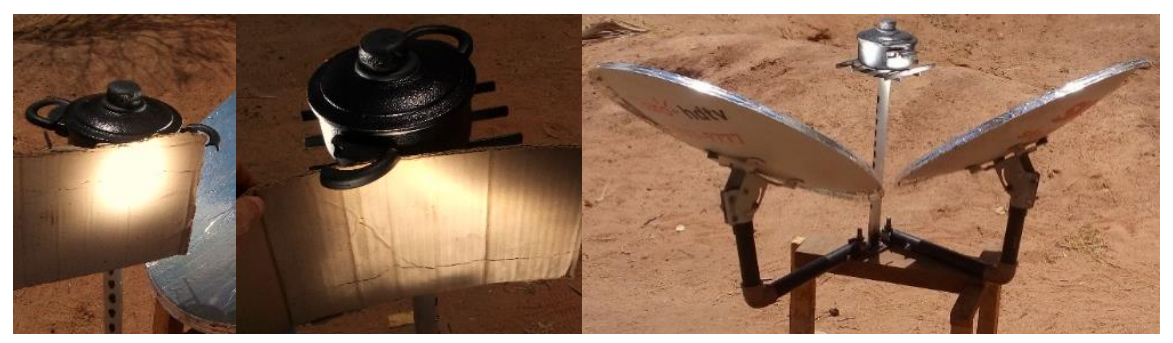

(a)

(b)

(c)

Figura 5. (a) e (b) Determinação do ponto focal dos refletores; (c) Panela centralizada no foco (Autoria própria).

É válido salientar, que as panelas utilizadas para a cocção dos alimentos são de alumínio de cor preta, tendo em vista que devido à cor escura, a taxa de absorção de irradiação térmica é mais elevada quando comparada com equipamento similar de cores mais claras.

A verificação e calibração do ponto focal dos refletores foram realizados no início de cada ensaio, com o auxílio de um anteparo situado próximo ao ponto focal, que neste caso, utilizou-se um pedaço de papelão. Ele foi posicionado ao lado da panela e realizado a regulagem dos refletores no ponto exato do foco. Nesse procedimento, observou-se que um refletor possuía o foco mais concentrado que o outro. Isso pode ser atribuído a dois fatores, sendo o primeiro que as duas antenas utilizadas no projeto são de fabricantes diferentes, $\operatorname{logo}$, pode haver alguma discrepância entre as dimensões específicas dos refletores; e o segundo, algum defeito imperceptível visualmente em sua geometria causada por um possível impacto mecânico.

\subsection{Ensaios realizados no protótipo desenvolvido}

Após a montagem do protótipo do fogão solar, realizou-se um teste experimental utilizando somente água na panela com o intuito de observar se os procedimentos de manuseio e regulagem dos focos configurar-se-iam 
conforme o esperado. Seguidamente, escolheu-se quatros alimentos para a realização dos ensaios, a saber, arroz, ovo, batata-doce e feijão.

Os experimentos de cocção dos alimentos foram realizados entre os dias 29/11/2019 e 05/12/2019 em horários que variaram das 10h25min às 12h25min na parte externa do Laboratório de Engenharias I, localizado no lado Leste da UFERSA campus Mossoró. Segundo [10], nesse período do ano é primavera no hemisfério sul e quase a totalidade do Nordeste é caracterizada pela ausência de chuvas e tempo seco, em especial no Rio Grande do Norte. O referido horário foi escolhido devido à tradição da maioria das famílias prepararem seus almoços nesse período do dia

Dando início aos experimentos, utilizou-se na realização das medições de temperatura e irradiância solar, respectivamente, um termômetro com infravermelho e um piranômetro. Nos instantes das medições, foram tomadas as devidas precauções de sempre realizá-las em um único ponto e por apenas um operador, diminuindo, dessa forma, as fontes de divergências nos resultados das leituras realizadas.

As medições foram efetuadas no momento inicial dos testes e em intervalos de 5 minutos. As duas leituras foram realizadas simultaneamente, utilizando a função "hold” de ambos os equipamentos, gravando os valores na tela dos dispositivos por alguns segundos, facilitando a coleta e transcrição dos dados manualmente para a tabela de dados.

\subsubsection{Cocção da batata-doce}

Os testes foram iniciados no dia 29/11/19, a partir das 10h50min, com a cocção de 320 gramas de batata-doce. Inicialmente, as batatas foram dispostas dentro da panela e em seguida adicionou-se água, aproximadamente $400 \mathrm{ml}$, de modo que as batatas ficassem submersas, de acordo com a Figura 6 (a). Em seguida, antes de iniciar o processo de cocção, colocou-se a panela no fogão solar e realizou-se a regulagem dos focos dos refletores.

Após aproximadamente 30 minutos do início do ensaio, percebeu-se a necessidade de regular os focos novamente, uma vez que os mesmos se encontravam divergentes em relação à panela. Para isso, foram realizadas duas regulagens. Na primeira a base foi rotacionada cerca de 15 graus no sentido horário; e na segunda, um refletor foi rotacionado verticalmente para cima, e o outro verticalmente para baixo, ambos em relação aos seus pedestais. A Figura 6 (b), evidencia as batatas cozidas após aproximadamente 50 minutos de cocção. Neste dia o céu apresentava algumas nuvens, fato que contribuiu para a redução da irradiação solar em determinados instantes, favorecendo à diminuição da temperatura nesses pontos.

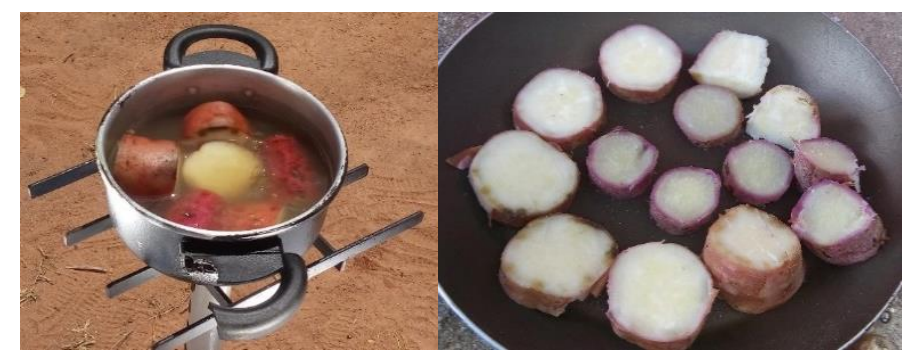

(a)

(b)

FiguRA 6. (a) Cocção das batatas; (b) Batatas cozidas (Autoria própria).

\subsubsection{Cocção do arroz}

O presente ensaio foi realizado no dia 03 de dezembro de 2019, a partir das 10h25min, com o objetivo de cozinhar uma porção referente a uma xícara de arroz, aproximadamente, 180 gramas. A priori, a panela foi 
levada ao fogão e, seguidamente, realizou-se a regulagem dos focos, vide Figura 7 (a). Posteriormente, o arroz foi refogado e adicionadas duas xícaras e meia de água em temperatura ambiente conforme indicado pelo fabricante. As medições de temperatura e irradiação solar foram efetuadas após a água ser adicionada, em intervalos de 5 (cinco) minutos.

No dia do experimento, o céu apresentava-se sem nuvens, indicando valores de irradiação bastante satisfatórios para o êxito da cocção. Após algo em torno de 23 minutos o arroz se encontrava completamente cozido, pronto para ser consumido, conforme evidenciado na Figura 7 (b).

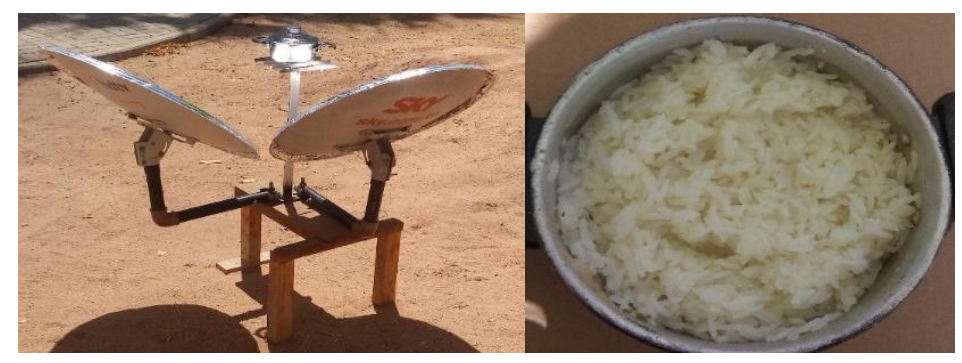

(a)

(b)

FIGURA 7. (a) Panela no ponto focal; (b) Porção de arroz cozido (Autoria própria).

\subsubsection{Cocção dos ovos}

O ensaio com os ovos ocorreu no mesmo dia que o ensaio anterior, iniciado às $11 \mathrm{~h} 20 \mathrm{~min}$, com objetivo de cozinhar três ovos no protótipo de fogão solar em questão. Inicialmente, adicionou-se, 400mL de água em temperatura ambiente à panela juntamente com os três ovos. Seguidamente, os refletores foram ajustados de forma que seus focos convergissem na panela. É oportuno ressaltar, que as condições climáticas estavam favoráveis, apresentando céu sem nuvens, fato que contribuiu para valores constantes de irradiação solar, denotando índices adequados para o êxito do ensaio.

As medições foram realizadas em intervalos semelhantes ao ensaio do item 3.2.2. Decorridos 20 minutos, o primeiro ovo foi retirado para ser avaliado em relação à cocção, sendo constatado que o mesmo se encontrava pronto para degustação e, consequentemente, os outros dois. A Figura 8 mostra em (a) o fogão solar em pleno funcionamento durante a cocção dos ovos, e em (b), os mesmos já cozidos.

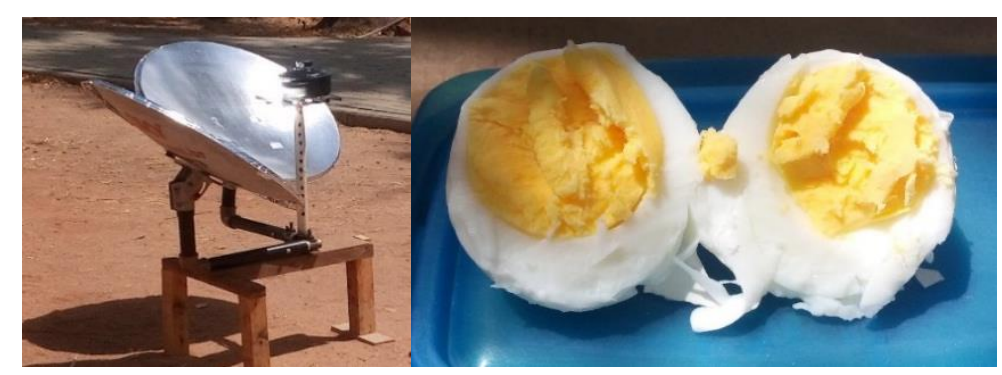

(a)

(b)

FIGURA 8. (a) Cocção dos ovos; (b) Ovos cozidos (Autoria própria).

\subsubsection{Cocção do feijão}

O ensaio foi realizado no dia 05/12/19, a partir das $10 \mathrm{~h} 25 \mathrm{~min}$, utilizando $180 \mathrm{~g}$ de feijão-de-corda. As medições e as regulagens inicial das superfícies refletoras foram realizadas conforme descrito no ensaio do item 3.2.2. No referido dia, o céu apresentava pouca nebulosidade, mas houveram momentos que as nuvens encobriram o sol, ocasionando redução tanto na temperatura no interior da panela quanto nos valores obtidos de 
irradiância solar. Ainda assim, após duas horas de cocção, pôde-se constatar que a devida porção encontrava-se cozida, pronto para ser consumida. Vale salientar que a cada 30 minutos, era necessário realizar a regulagem dos focos conforme citado no item 3.2.1. Na Figura 9 (a), é possível observar a panela no centro focal e em (b), o feijão já cozido.

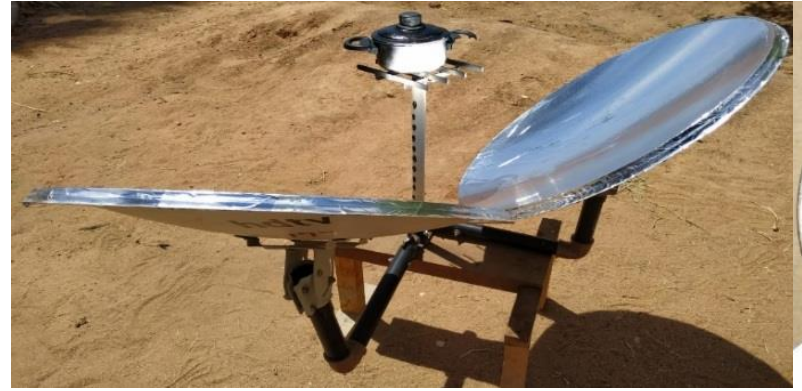

(a)

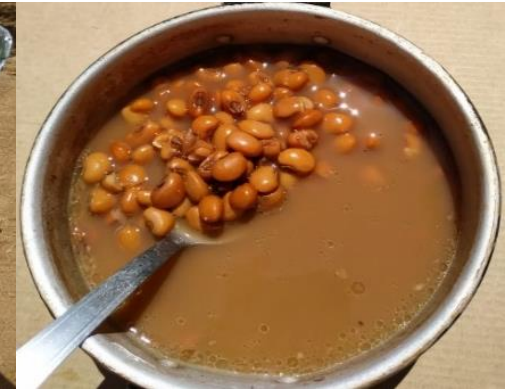

(b)

FIGURA 9. (a) Fogão solar em pleno funcionamento, com a panela no centro focal; (b) Feijão totalmente cozido (Autoria própria).

\section{ANÁLISE DOS RESULTADOS}

De posse dos valores obtidos nas medições da temperatura e irradiância solar realizadas a cada 5 (cinco) minutos, juntamente com seus respectivos horários, gráficos foram elaborados contendo as informações de cada ensaio. A partir desses dados, tornou-se possível visualizar a influência da irradiância solar sobre as temperaturas obtidas, e por decorrência, o tempo de cozedura dos alimentos. Após cada ensaio e comprovação da cozedura dos alimentos, os mesmos foram degustados, apresentando texturas e sabores semelhantes em relação aos alimentos preparados, por ex., no fogão a gás. As seções 4.1.1, 4.1.2, 4.1.3 e 4.1.4 apresentam os resultados destas análises para cada tipo de alimento submetido à cocção.

\subsubsection{Cocção da batata-doce}

A Figura 10 representa as curvas da temperatura e irradiação solar em função do tempo referentes aos dados coletados no processo de cocção da batata-doce.

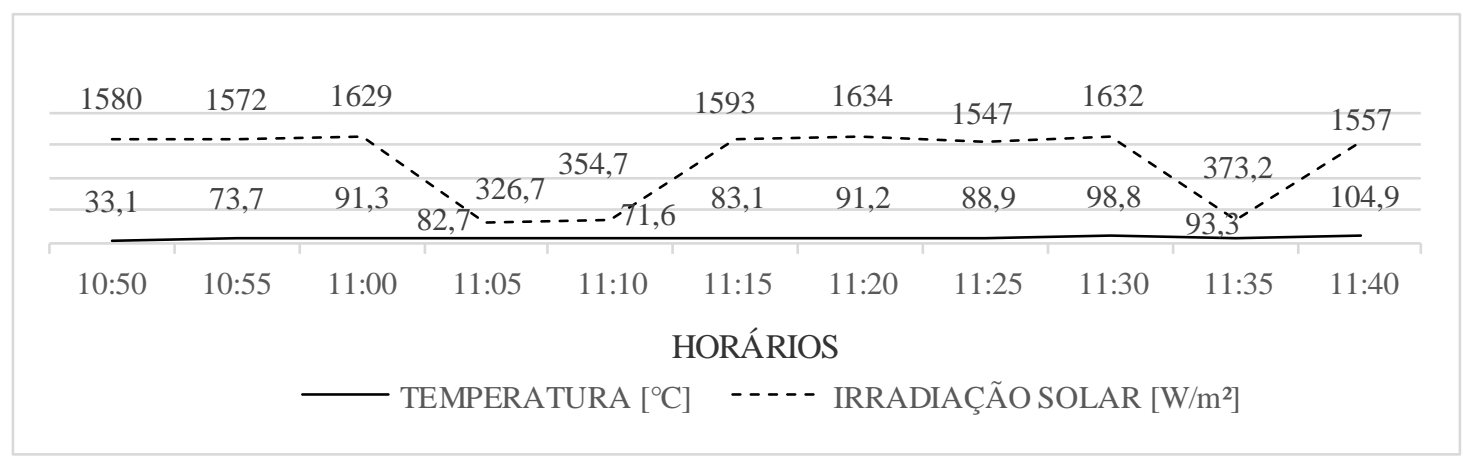

FIGURA 10. Cocção da batata-doce (Autoria própria).

\subsubsection{Cocção do arroz}

O Figura 11 mostra os resultados obtidos das medições realizadas. Pode-se perceber que os valores da irradiação estão aproximadamente uniformes, fato esse que reflete diretamente no aumento e na conservação das temperaturas. 


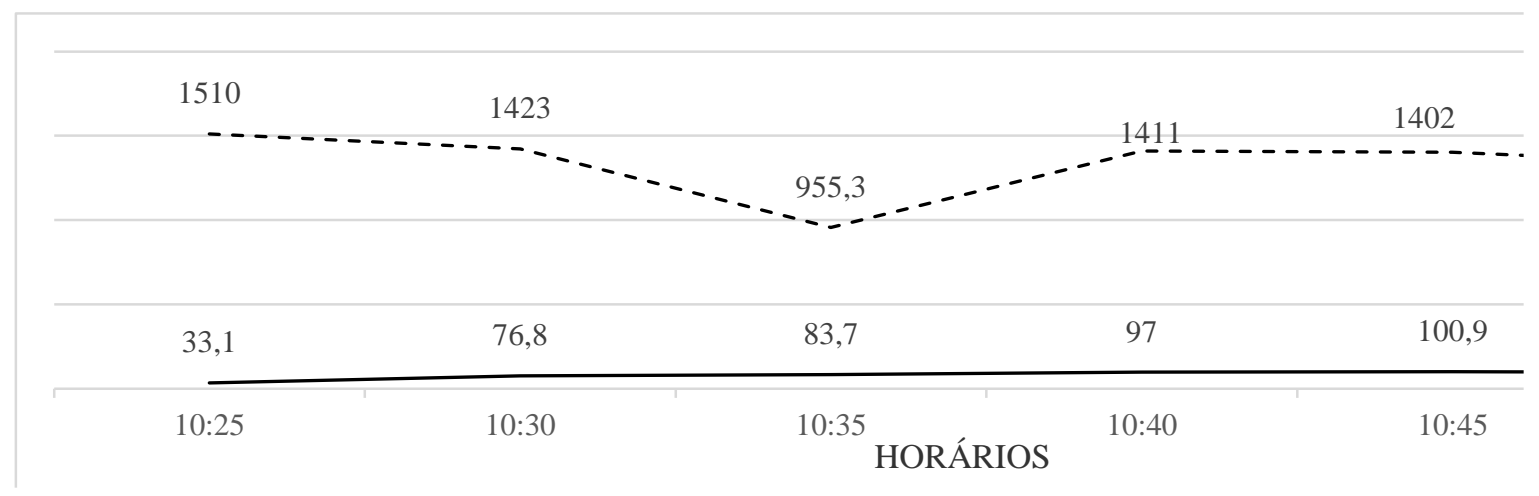

FIGURA 11. Cocção do arroz (Autoria própria).

\subsubsection{Cocção dos ovos}

A Figura 12 denota o comportamento das temperaturas e irradiação solar obtidas em função dos horários de medições. Ao analisar o mesmo, é visível a estabilidade da irradiação solar, fato esse que afeta diretamente nos bons resultados obtidos das temperaturas atingidas.

\begin{tabular}{|c|c|c|c|c|}
\hline 1331 & 1293 & 1318 & 1289 & 1302 \\
\hline \multicolumn{5}{|c|}{ - - - - - } \\
\hline 33,6 & 80,6 & 90,7 & 100,2 & 100,8 \\
\hline $11: 20$ & $11: 25$ & $11: 30$ & $11: 35$ & $11: 40$ \\
\hline & FEMPER & ORÁR & 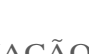 & \\
\hline
\end{tabular}

FIGURA 12. Cocção dos ovos (Autoria própria).

\subsubsection{Cocção do feijão}

Averiguando-se a Figura 13, pode-se notar o comportamento da temperatura e irradiação solar em função do tempo. É notável a excelência nos valores obtidos da irradiação e, consequentemente, da temperatura, havendo, entretanto, um intervalo de 20 minutos onde ocorreu redução significativa das duas variáveis analisadas devido à presença de nuvens espaçadas.

É oportuno salientar que foi necessário adicionar mais água em temperatura ambiente à panela por duas vezes. A primeira vez às $11 \mathrm{~h} 25 \mathrm{~min}$, e a segunda, $11 \mathrm{~h} 55 \mathrm{~min}$. Esse fato levou à redução momentânea no valor da temperatura na panela, mas devido aos valores satisfatórios da irradiação, logo a mesma se restabeleceu. 


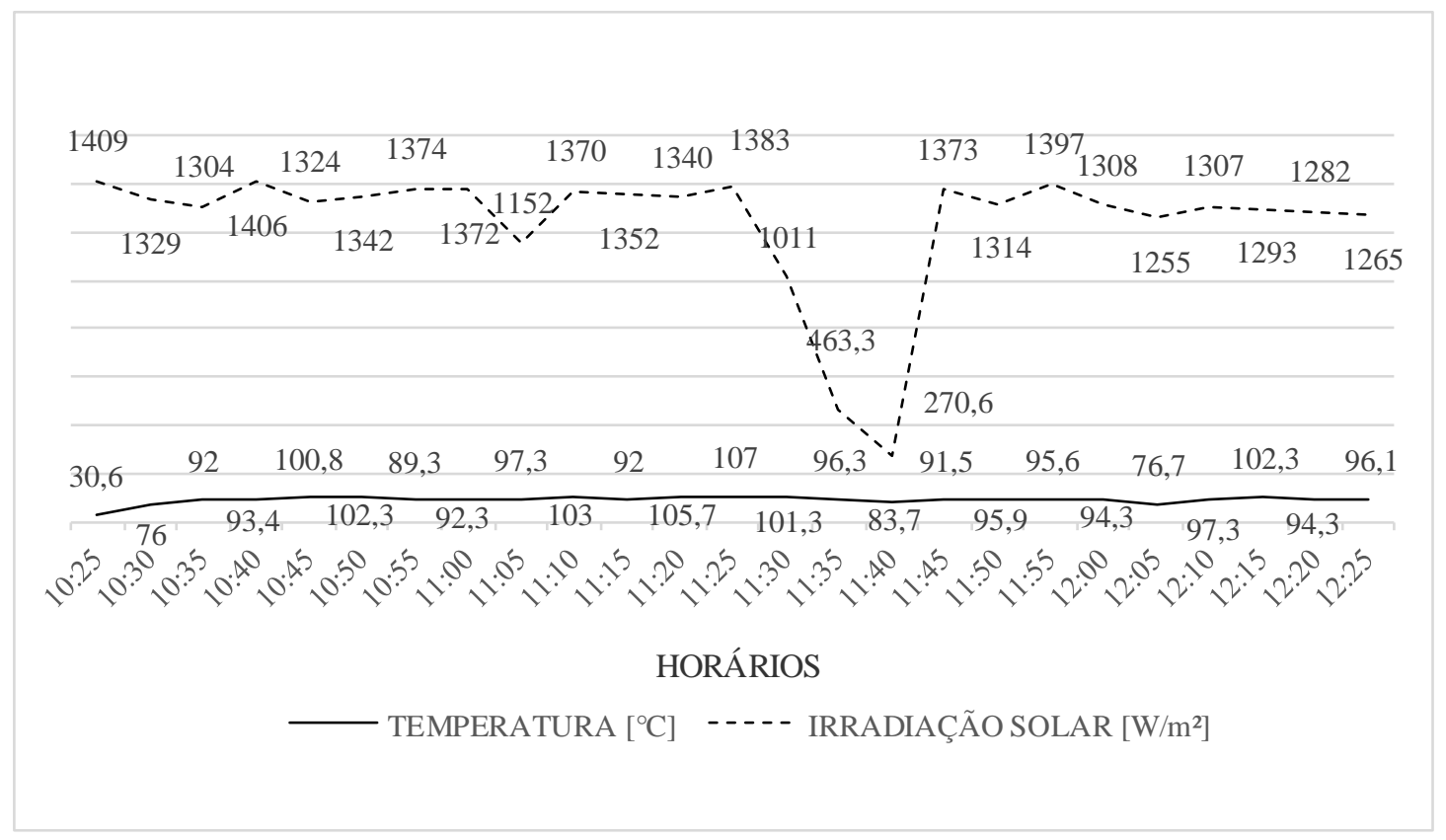

FIGURA 13. Cocção do feijão (Autoria própria).

\subsection{Análise entre o Fogão Solar versus Fogão a Gás}

Com o intuito de verificar o desempenho do fogão em estudo, os dados obtidos nos ensaios dos itens 3.2.1, 3.2.2, 3.2.3 e 3.2.4 foram comparados com os dados do fogão convencional a gás, confrontando o tempo de cocção dos alimentos preparados. A Tabela 1 indica os alimentos submetidos aos ensaios com suas respectivas quantidades, tempo de cocção no fogão solar elíptico e tempo estimado de cozedura no fogão a gás. É válido salientar que os valores denotados na última coluna da Tabela 1 representa o tempo estimado de cocção dos referidos alimentos conforme [11], sendo estes sujeitos à alteração, dependendo tanto das características físicas do fogão a gás quanto das propriedades intrínsecas dos alimentos.

TABELA 1. Comparação entre o tempo de cocção do fogão solar e a gás (Autoria própria).

\begin{tabular}{cccc}
\hline Alimentos & Quantidade & $\begin{array}{c}\text { Tempo de cocção no } \\
\text { fogão solar (minutos) }\end{array}$ & $\begin{array}{c}\text { Tempo de cocção no } \\
\text { fogão a gás (minutos) }\end{array}$ \\
\hline Batata-doce & 320 gramas & 50 & $25-35$ \\
Arroz & 180 gramas & 23 & $15-20$ \\
Ovos (gema dura) & 3 unidades & 20 & $10-13$ \\
Feijão & 180 gramas & 120 & $50-60$ \\
\hline
\end{tabular}

Observando a Tabela 1, é possível perceber que o tempo de cocção da batata-doce, ovos e feijão é praticamente o dobro quando comparado ao fogão a gás, com exceção do arroz que obteve tempo semelhante.

Mesmo apresentando o dobro de tempo na cocção de alguns alimentos na comparação supracitada, o fogão solar em estudo expressou bons resultados nos ensaios realizados, visto que a cocção foi concluída em todos os testes. Outra vantagem a ser analisada é o custo-benefício, pois em sua confecção o custo monetário foi de aproximadamente $\mathrm{R} \$ 60$. Com este valor foi possível comprar uma antena de TV usada por R $\$ 40$, uma fita adesiva cromada por $\mathrm{R} \$ 4$, e os $\mathrm{R} \$ 16$ restantes foram utilizados na compra de lixa, parafuso, tinta preta e 
conexões de PVC. Vale ressaltar que os outros componentes como madeira, eletroduto, retalhos de ferro e a outra antena, foram adquiridos por meio de doações, aumentando a viabilidade de construção do fogão em estudo.

\subsection{Fenômenos observados durante o processo de cocção dos alimentos}

Durantes os ensaios, percebeu-se que a água contida na panela para a cocção dos alimentos iniciava o processo de ebulição mais rápido em um lado que do outro, evidenciando que a temperatura no interior da mesma não estava uniforme. Esse fato se deve ao tipo de fogão utilizado, haja vista que devido aos pontos focais dos refletores serem próximos à superfície de reflexão, os mesmos são impossibilitados de convergirem se ambos estiverem com os refletores na posição horizontal. Portanto, este fogão solar apresenta a maior porção de incidência dos raios na lateral da panela, e não no fundo da mesma, como nos casos dos fogões a gás, lenha e solar parabólico.

Na tentativa de contornar essa questão, foi necessário girar a panela em sua base por várias vezes, no intento de que a temperatura em seu interior ficasse a mais uniforme possível, fazendo a cocção dos alimentos por igual. Dessa maneira, após a cozedura, os aspectos visuais dos alimentos assemelhavam-se aos do modo de cocção tradicional. No sabor, por exemplo, não houve diferença significativa que pudesse ser questionada quanto ao método utilizado na cocção, ficando evidenciado a eficácia de tal modo de cocção de forma alternativa às opções tradicionais.

Outro fato importante observado nos ensaios refere-se à proteção da pele e dos olhos durante o manuseio com o fogão. Devido às condições impostas em tal modalidade de cocção, até mesmo em função do horário de uso para preparo dos alimentos, deve-se sempre utilizar equipamentos de proteção como protetor solar, óculos de sol e roupas longas com proteção UV, pois mesmo com pouca exposição, a médio ou longo prazo a referida exposição poderá prejudicar a saúde do usuário exposto.

Analisando os gráficos mostrados nas Figuras de 10 a 13, pode-se perceber que nos dias e horários neles especificados, a água no interior da panela entrava no processo de ebulição em aproximadamente 15 minutos após o início dos ensaios, e que nos instantes que a irradiação solar tornava-se ínfima, a temperatura logo diminuía. Entretanto, não se sabe ao certo se essa rápida variação de temperatura é ocasionada pela condutividade térmica do material da panela ou se pode ser devido a fatores externos como o vento, por exemplo, mas é visível que tais alterações influenciam na eficiência do fogão.

\section{CONCLUSÃO}

Mediante o desenvolvimento do protótipo de fogão solar tipo elíptico móvel apresentado no vigente trabalho, é possível afirmar claramente que o mesmo apresenta-se como uma tecnologia alternativa viável nas condições climáticas e geográficas analisadas neste trabalho para o processo de cocção de alimentos.

A comparação entre o fogão solar elíptico e o fogão a gás indicou que o protótipo desenvolvido neste estudo mostra-se eficaz, mesmo havendo uma certa discrepância entre os tempos de cocção dos fogões em análise. Dos quatro ensaios realizados, apenas o tempo de cocção arroz assemelhou-se ao do fogão a gás, tendo os outros três levado aproximadamente o dobro do tempo para a finalizar seu processo de cozedura. Esse fato não põe à prova o desempenho do fogão solar elíptico móvel confeccionado neste estudo, visto que a cocção foi concluída em todos os ensaios e o custo-benefício o faz ser uma tecnologia atrativa.

Em termos de custo-benefício o presente fogão mostrou-se atrativo, haja vista que a sua confecção foi realizada com custo monetário de $\mathrm{R} \$ 60$, visto que boa parte dos materiais utilizados foram reciclados e recebidos de doações, contribuindo significativamente para a produção e disseminação desta tecnologia. 
Mecanismos para o aprimoramento do ajuste da posição focal e métodos de conservação térmica da panela utilizada com materiais ou compósitos isolantes devem fazer parte de futuros estudos e ensaios dessa técnica de cocção, pois verificou-se que a temperatura no interior da panela diminui bastante ao acontecer um sombreamento do fogão, mesmo que por poucos instantes.

Nessa conjuntura, configura-se como uma excelente opção a utilização de fogões solares em algumas regiões do semiárido nordestino, visto que são áreas privilegiadas no que se refere ao recurso solar, e vale destacar também a simplicidade de confecção do protótipo desenvolvido utilizando material reaproveitável que seriam descartados.

\section{REFERÊNCIAS}

[1] QUEIROZ, F. W. Construção de um Fogão Solar à Concentração para Cozimento Direto e Indireto. 2005. 96f. Dissertação (Mestrado em Engenharia Mecânica), Departamento de Engenharia Mecânica, Programa de Pós-Graduação em Engenharia Mecânica, Universidade Federal do Rio Grande do Norte, Natal, 2005.

[2] RAMOS FILHO, R. E. B. Análise de desempenho de um fogão solar construído a partir de sucatas de antena de TV. 2011. 96 f. Dissertação (Mestrado em Engenharia Mecânica), Universidade Federal do Rio Grande do Norte, Natal, 2011.

[3] BESSA NETO, L. J. et al. Fogão Solar Parabólico x Fogão Solar Tipo Caixa. R4EM 2019, Volume 1, 8 páginas.

[4] AGÊNCIA NACIONAL DE ENERGIA ELÉTRICA. Banco de Informação de Geração - BIG. Disponível online: <http://www2.aneel.gov.br/aplicacoes/ResumoEstadual/CapacidadeEstado.cfm> (acesso em: 28/05/2020).

[5] SOUZA, L. G. M. M. Viabilidades Térmica, Econômica e de Materiais da Utilização de Tubos de PVC como Elementos Absorvedores em Coletores de um Sistema de Aquecimento de Água por Energia Solar. Tese (Doutorado em Ciência e Engenharia de Materiais), Programa de Doutorado em Ciência e Engenharia de Materiais, Universidade Federal do Rio Grande do Norte, Natal, 2002.

[6] RAFSUNJANI, Md; JOYEE, E. B.; RAHMAN, A. N. M. Development and Testing of a Two-axis Tracking Spherical Solar Cooker. IEEE Xplore. p.1-8, 2016. DOI: 10.1109/ICDRET.2016.7421500.

[7] LIMA, R. R. Fabricação e Estudo de Um Fogão Solar à Concentração Mono e Bifocal. 2018.58 f. Monografia (Graduação em Engenharia Mecânica), Universidade Federal do Rio Grande do Norte, Natal, 2018.

[8] LOPO, A. B. Análise do Desempenho Térmico de um Sistema de Aquecimento Solar de Baixo Custo. 2010. 81f. Dissertação (Mestrado em Engenharia Mecânica), Departamento de Engenharia Mecânica, Programa de Pós-Graduação em Engenharia Mecânica, Universidade Federal do Rio Grande do Norte, Natal, 2010.

[9] DANTAS, R. A. R. Construção e Análise Térmica de um Fogão Solar de Baixo Custo Tipo Concentrador em Mossoró/RN. 2015. 54f. Monografia (Graduação em Engenharia de Energia), Departamento de Ciências Ambientais e Tecnológicas, Universidade Federal Rural do Semiárido UFERSA, 2015.

[10] CENTRO DE PREVISÃO DE TEMPO E ESTUDOS CLIMÁTICOS - CPTEC. Disponível online: $<$ https://clima1.cptec.inpe.br/estacoes> (acesso em 03/06/2020).

[11] TEMPO DE COZIMENTO. Disponível online: <https://tempodecozimento.com.br> (acesso em 06/07/2020). 